\title{
The expression of miRNA-155 and hypoxia inducible factor alpha (HIF1A) mRNA in the early and advanced stages of ovarian cancer patients blood plasma
}

\author{
S.N. Chasanah ${ }^{1 *}$, A.S. Fitriawan ${ }^{1}$, F.K. Pukan ${ }^{1}$, A.I. Kartika ${ }^{2}$, R, Oktriani ${ }^{3}$, A. \\ Trirahmanto ${ }^{4}$, H. Pradjatmo ${ }^{4}$, T. Aryandono ${ }^{5}$, S.M. Haryana ${ }^{6}$ \\ ${ }^{1}$ Basic Medical Science and Biomedicine Program, Faculty of Medicine, Universitas \\ Gadjah Mada, Yogyakarta, Indonesia. ${ }^{2}$ Graduate Program in Biotechnology, School \\ of Postgraduate, Universitas Gadjah Mada, Yogyakarta, Indonesia. ${ }^{3}$ Department of \\ Biochemistry Faculty of Medicine, Universitas Gadjah Mada, Yogyakarta, Indonesia. \\ ${ }^{4}$ Department of Obstetry Gynecology, RSUP Dr. Sardjito, Yogyakarta, Indonesia. \\ ${ }^{5}$ Department of Surgery, Faculty of Medicine, Universitas Gadjah Mada, Yogyakarta, \\ Indonesia. 'Department of Histology and Cellular Biology, Faculty of Medicine, \\ Universitas Gadjah Mada, Yogyakarta, Indonesia.
}

DOI: http://dx.doi.org/10.19106/JMedScieSup004804201620

\section{ABSTRACT}

Ovarian cancer carries high burden of disease, and its mortality rate comprises half the reported death cases in gynecological malignancy. Ovarian cancer is the second most common cancer in women, following cervical cancer. The process of ovarian carcinogenesis occurs at the molecular level and is regulated by microRNA. Previous in-silico research revealed that microRNA-155 (miRNA-155) targets the HIF1A mRNA, the regulator gene in hypoxia. HIF1A is involved in various hallmarks of cancer, and also thought to play roles in Warburg effect as well as genetic transcription factors in angiogenesis. Regulation of miRNA-155 and HIF1A is thought to be involved in the process of ovarian cancer progression, thus possess the potential as minimally-invasive prognostic biomarker. This study aimed to determine the differences expression of the miRNA-155 and HIF1A in the blood plasma collected from both early- and advanced-stage ovarian cancer patients. The blood plasma samples were taken from 32 early-stage ovarian cancer patients and 20 advanced-stage patients admitted to RSUP Dr. Sardjito. Total RNA was isolated from blood plasma, then cDNA synthesis was performed to obtain the cDNA. The expression of miRNA-155 and HIF1A were calculated using qPCR, and its results were analyzed using Biorad CFX Manager Software. The analysis revealed that the expression of miRNA-155 were 2.18 folds lower ( $p$-value $=0.018$ ) in plasma of advanced-stage ovarian cancer patients compared to those at early stage. The expression of HIF1A were 2.46 folds higher ( $p$-value $=0.039$ ) in plasma of advancedstage patients compared to those at early stage, and both results are statistically significant ( $p$ value $\leq 0.05$ ). In conclusion, our study showed that miRNA-155 expression is downregulated in advanced-stage ovarian cancer compared to earlystage, and followed by upregulation of mRNA expression in HIF1A.

Keywords: plasma; ovarian cancer; miRNA-155; HIF1A

Corresponding author: siti.nurchasanah@mail.ugm.ac.id 